\title{
Telemetry reveals how river connectivity affects fish ecology
}

\section{Human impacts on river} systems have reduced connectivity by creating barriers that often prevent fish passage. The Lake Winnipeg has used acoustic telemetry to track fish migration along the river system and build vital knowledge and understanding of fish ecology. The results will inform river restoration and conservation of two fish species, the Channel Catfish and Bigmouth Buffalo.

ivers have long been a vital resource for human success,
providing a wide range of eficial services. They give us food and hydropowy. Howpor, ing numerous activities which have take place throughout human history have often resulted in detrimental impacts on river systems.

While the impact of human activity on water quality is an immediately recognisable issue, an equally significant problem is created by changes to river connectivity. Human infrastructure, such as weirs, dams, sluices or diversions, can fragment a river and restrict species movement along its length. Where this preven access to suitable habitat for reproductive behaviours or juvenile in population declines. Populations discoutic species can also become disconnected. These populations can and so struge or eproductively isolated and abiotic environmental pressures.

Anthropogenic obstacles also alter the speed, volume and turbidity of flow, as well as altering the diversity, quality and quantity of suitable habitat. Aquatic animals often favour, or require, different depths, substrates and speed of flow across life stages and behaviours. Therefore, river connectivity is a major issue for conservation ecology with important implications for species diversity and population dynamics.

JUST KEEP SWIMMING Migration, the large-scale movement f members of a species, is a component

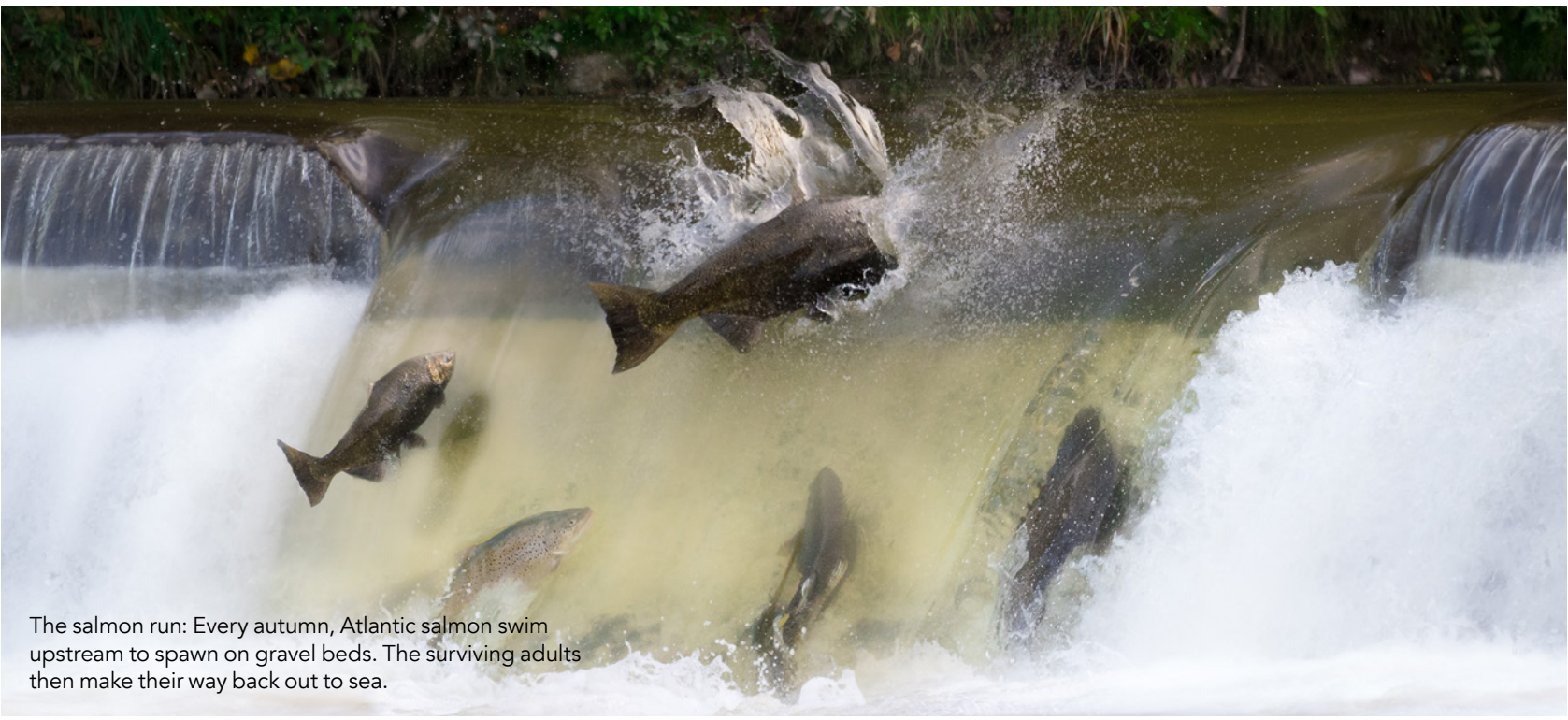

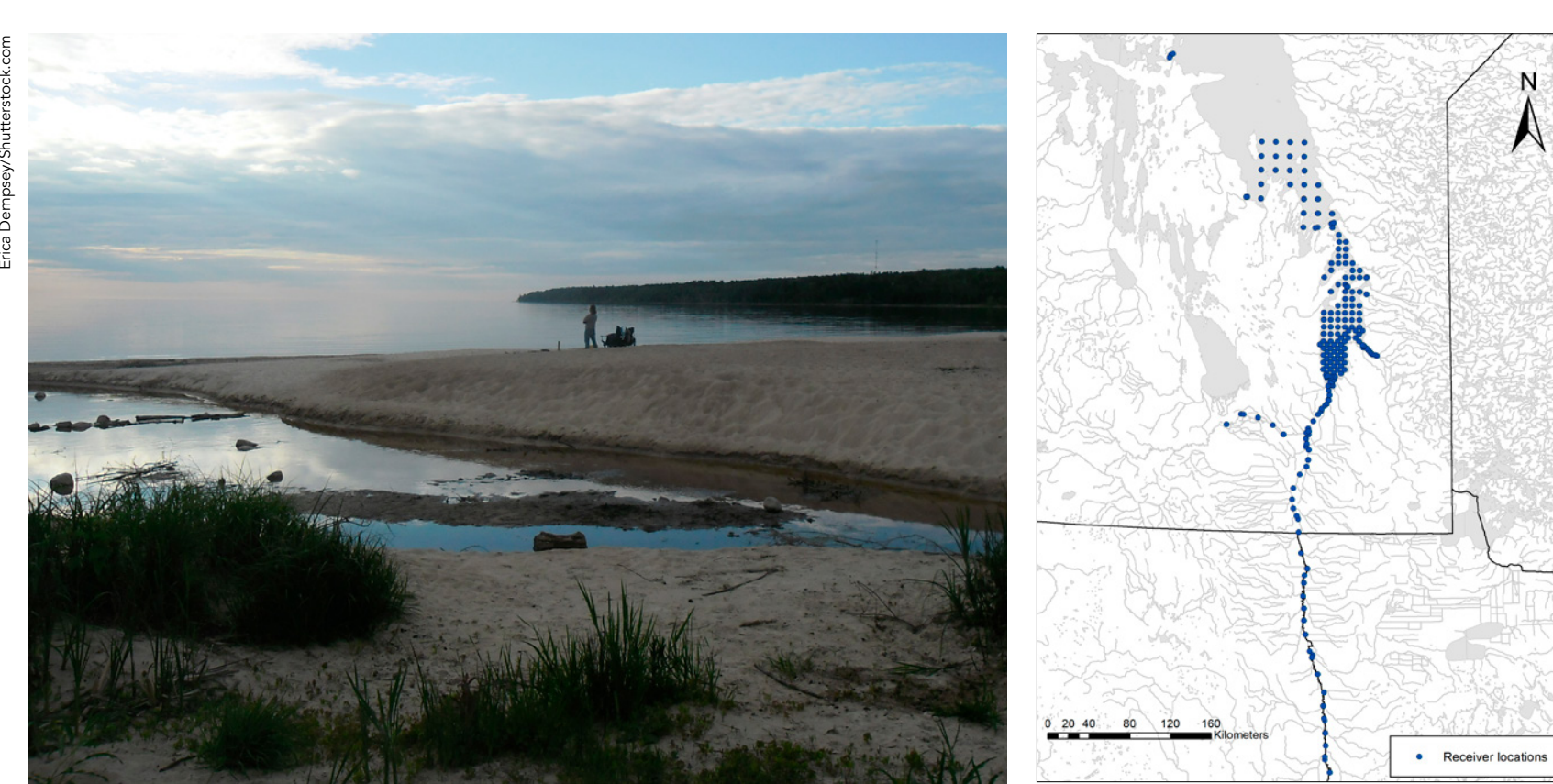

Lake Winnipeg is home to one of the largest hydro-reservoirs in the world (left). The Lake Winnipeg Fish Movement Study covers a broad geographical range to change their environment to find more favourable conditions. Migration is response to resource needs at different eight hydroelectric dams. Productive life stages. In aquatic animals, particularly commercial and recreational fisheries fish, a number of species such as salmon migrate from freshwater to saltwater (anadromous) or, like eels, from saltwater to freshwater (catadromous) for spawning. Adults then make the return journey and spawning grounds become nursery grounds for juvenile life stages. If these migratory routes are blocked, it can caus population declines and local extinctions in certain species. However, not all species migrate from or to saltwater regions. Fish bach mignate with ' a freshwer' many of these species the scale of their movementand size of their home range remains largely unknown.

Barriers within the river basin not only impact larger species whose movement can be entirely restricted: changes in predation and food availability will also have consequences for the entire aquatic community. Restoring connectivity is therefore a major goal for conservation efforts, fisheries management and river restoration projects.

\section{LAKE WINNIPEG BASIN}

Lake Winnipeg is the largest lake in Manitoba, Canada, and is one of the largest hydro-reservoirs in the world. The main tributaries of Lake Winnipeg, the Red River of the North

The project not only covers a broad geographical range, but has also monitored several key species over six years. Of particular interest are two fish species, the Bigmouth Buffalo (Ictiobus cyprinellus), whose population declines are thought to be a result of river and the Channel Catfish (Ictalurus punctatus), which is a host species for the endangered Mapleleaf freshwater mussel (Quadrula quadrula) as well a $\begin{array}{ll}\text { stakeholders in order to inform fisheries trophy species for recreational fishing. } \\ \text { management and river restoration. } & \text { These species are also useful indicator }\end{array}$ W a collaborative project aiming to ack

Acoustic telemetry is a popular tool as it provides abundant data without the vast sample size required for traditional techniques.

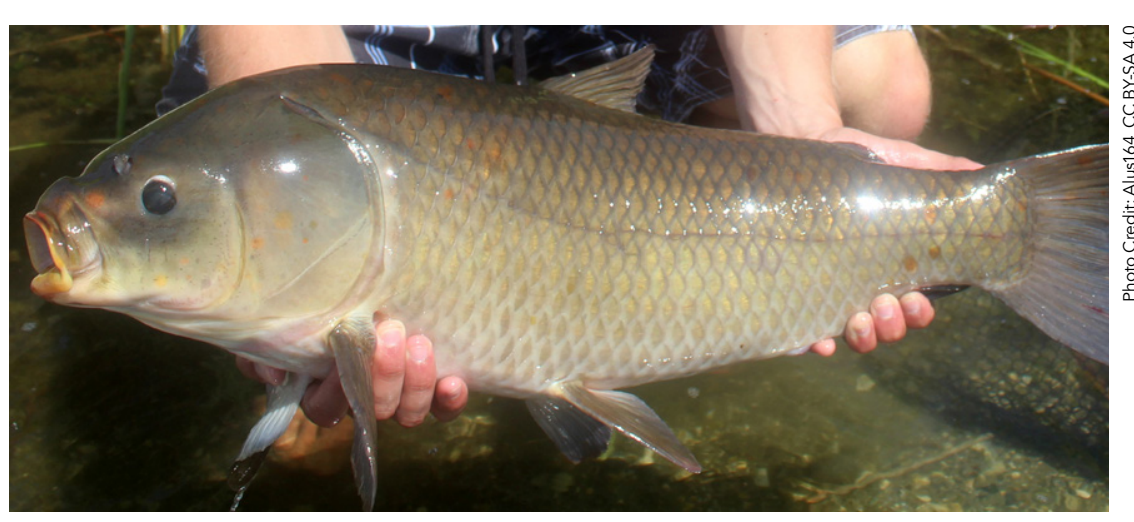

The Bigmouth Buffal ${ }^{\prime}$ s population decline is thought to be the result of river fragmentation and water
management practices that have led to the elimination and/or degradation of spawning habitat. 


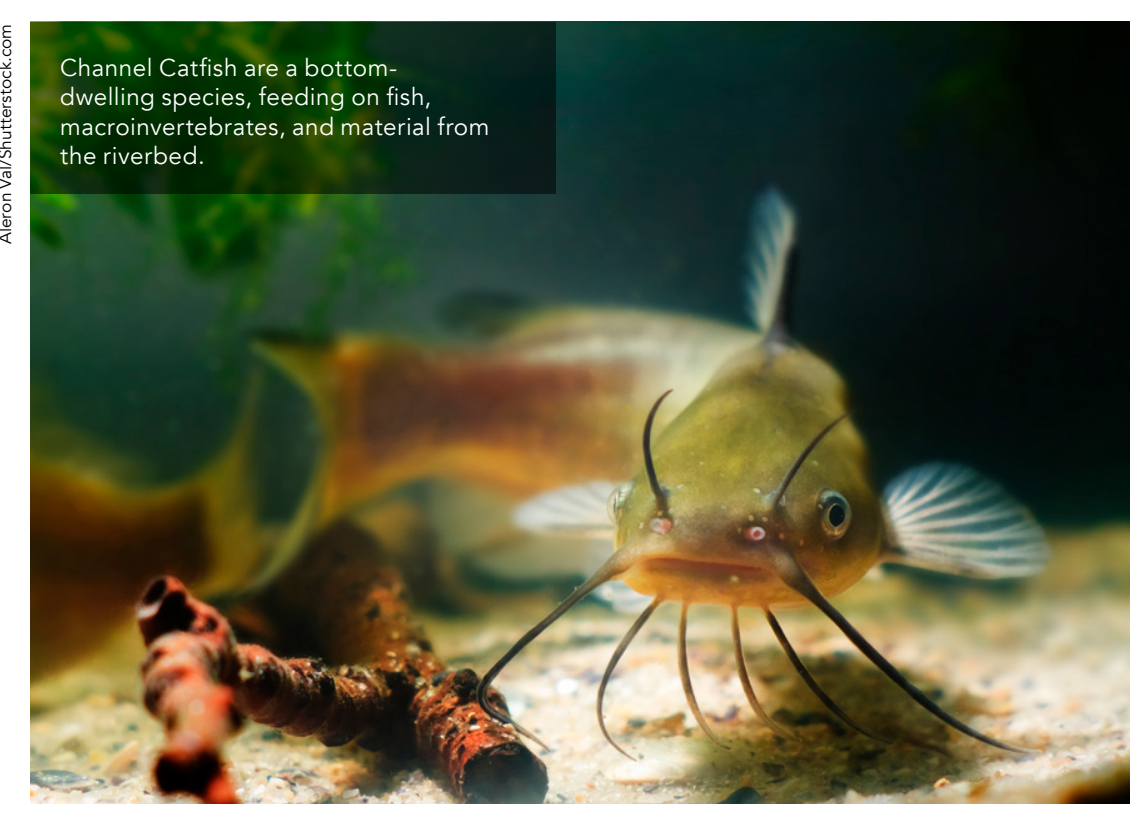

Restoring connectivity is a major goal for conservation efforts, fisheries management and river restoration projects.

species in this system due to their contrasting ecology. The Bigmouth Buffalo are filter-feeders that use fine gill rakers to strain food items from the surface and middle of the water column. In contrast, Channel Cattish are a bottom-dwelling (benthic) species, feeding on fish, macroinvertebrates, and material from the riverbed.

\section{TRACKING FISH MOVEMENT} Acoustic telemetry has become widespread and popular tool for investigating aquatic animal ecology, as vast sample size required for tradition mark-recapture techniques. Fish were caught using a mixture of electrofishing, angling and gill netting and acoustic transmitters were implanted in the

body cavity. Over 200 receivers were then installed in a grid system across Lake Winnipeg and along the two main tributaries to capture data from the transmitters. Data simulation work within the research team had shown grid sampling can improve the accuracy of movement data compared with previously used linear approaches,

The telemetry data provided valuable insights into the movement patterns of the two species both in terms of location and time. Bigmouth Buffalo were home range compared to the Channe Catfish. In addition, the data suggested the activity levels of both were higher during the open water season betwe April and October, compared to

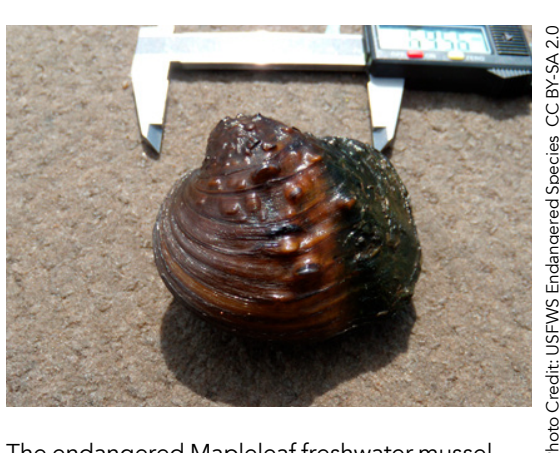

The endangered Mapleleaf freshw
uses the Channel Catfish as a host.

during the ice-on season (November to March). The data also allowed the researchers to identify locations currently creating bottlenecks for connectivity and highlighted particular estriction in the upstream movement of both species across dams and other was less resicted.

As well as providing data on connectivity, the data also suggested interesting timing of movement in relation to water flow. Both species appeared to be triggered into movement by peak flows. Further investigation of this are will be needed to manage passage and provide further information for fisheries conservation management.

CONSERVATION AND RESTORATION This study has provided evidence of the problems human infrastructure barriers can create for potadromous fish species migrating within freshwater basins. The team hope this data will help find solutions by informing fisheries priorities. The collaborative nature of the project has brought together stakeholders with differing questions and priorities for whom the river is a shared resource.
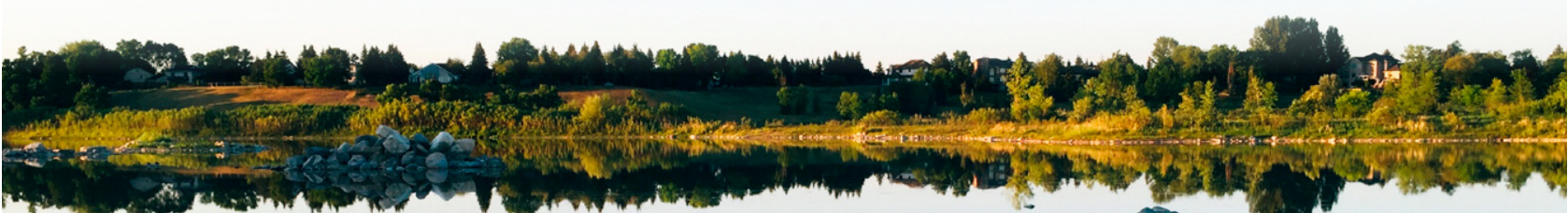

\section{Behind the Research}

a

Dr Eva

Enders

E: eva.enders@dfo-mpo.gc.ca

W: https://profils-profiles.science.

g.ca/en/profile/eva-enders

Research Objectives

The Lake Winnipeg Basin Fish Movement Project has been tracking the movements patterns of fish to understand migration spawning site fidelity, mortality, and habitat use.

\section{Detail}

Dr Eva Enders

Sol University Crescent, Winnipeg,

Manitoba, R3T 2N6,

Doug Watkinson

Manitoba, R3T 2N6, Canada

Dr Mark Pegg

(02 South Hardin Hall, 3310 Holdrege USA

Bio

Dr Eva Enders is a Research Scientist at Fisheries and Oceans Canada. conservation physiology, fish behaviour and bioenergetics, and aquatic ecology to provide science advice on species at risk, fish and
fish habitat protection, and aquatic

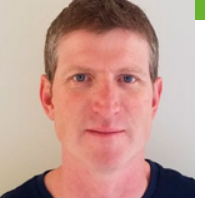

Doug

E: doug watkinson@dfo-mpogcca

Watkinson

E: doug.watkinson

vasive species.

\section{References}

Kraus, R.T., Holbrook, C.M. Vandergoot, CS. Stewart, TR, Faus, M. .., Walkinson, D.A.A., Charles, C., Pegg, M., Enders, E.C., \& Kruger, C.C. (2018). Evaluation of acoustic telemetry grids tor determining aquatic animimal movement and surviva

Enders, E.C., Charles, C., Watkinson, D.A., Kovachik, C Leroux, D.R., Hansen, H., \& Pegg, M.A. (2019). Analysing habitat connectivity and home ranges of Bigmouth Buffalo network. Sustainability, 11(11), 3051

Hansen, H., Pegg, M., Van Den Broeke, M., Watkinson D.A., \& Enders E.C. (2020). An unseen synchrony or recurrent resource pulse opportunity? Linking fisheries with Available at: https//doiorg/10.1002/rse? 147

Doug Watkinson is a Research
Biologist with Fisheries and Oceans
Canada, and studies distribution,
systematics/taxonomy, ecology, and
population biology of freshwater fish
His research is focused on species at
risk, anthropogenic habitat impacts,
and aquatic invasive species. He is a
member of the COSEWIC Freshwate
Fishes Specialist Subcommittee.
He co-authored The Freshwater
Fishes of Manitoba.
Dr Mark Pegg is a fish ecologist and
professor in the School of Natural
Resources of the University of
Nebraska-Lincoln. His research is
centred around the ecology of flowing
systems, fisheries management, the
impacts of aquatic nuisance species,
and restoration ecology.

Funding - Intenational Watershed Initiative through the International
Joint Commission - Fisheries and Oceans Canada's (DFO) Partnership Fund, - Fish Habitat Protection progh and - Fish Futures Inc - Manitoba Fish and Wildlife - Enhancement Fund fincoln

Collaborators - Manitoba Agriculture and Resource of Natural Resources Fish Department - Lakehead University - Lake Winnipeg Foundation

\section{Personal Response}

\section{What have the three of you found most rewarding} about your work on this project?

II Bigmouth Buffalo is a species native to the St longest-living freshwater fish species. Using acoustic telemetry to track Bigmouth Buffalo movement patterns, it was exciting to see the large-scale roaming behaviour
of Bigmouth Buffalo through the Red River system that

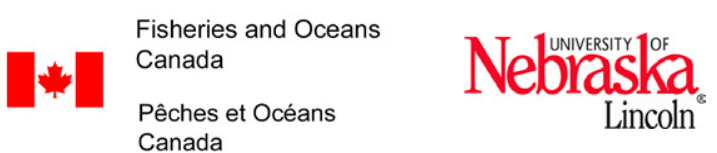
Lawrence, Mississippi, and Hudson Bay drainages where
it occurs in large river system. It is likely also one of the 